\title{
Su Ortamından Mikroplastik Giderimine Genel Bakış
}

\author{
Olcay Gülçiçek Uysal ${ }^{1 *}$ \\ 1Mersin Üniversitesi, Mühendislik Fakültesi, Çevre Mühendisliği Bölümü, Mersin, Türkiye, (ORCID: 0000-0001-9032-4241), olcayozer@mersin.edu.tr
}

(1st International Conference on Applied Engineering and Natural Sciences ICAENS 2021, November 1-3, 2021)

(DOI: 10.31590/ejosat.1015586)

ATIF/REFERENCE: Gülçiçek Uysal, O. (2021). Su Ortamında Mikroplastik Giderimine Genel Bakış. Avrupa Bilim ve Teknoloji Dergisi, (28), 1404-1409.

\section{Öz}

Plastik ürünler dünya çapında çoğu toplum tarafından kullanılmaktadır ve bunların üretimi, ilk ticari gelişmelerinden bu yana önemli ölçüde artmıştır. 5 mm'den küçük partiküller mikroplastik olarak tanımlanır. Son yılların en önemli kirleticisi haline gelen mikroplastikler, ekosistemin tüm kompartımanlarında ciddi birikim ve tehlikeye neden olmaktadır. Bu çalışma ile mikroplastiklerin yapısı ve bugüne kadar su ortamından giderimi üzerine yapılmış çalışmaların sonuçları ve karşılaştırılması yapılmıştır.

Anahtar Kelimeler: Mikroplastik Kirliliği, Giderim Yöntemleri, Sucul Ortam.

\section{Overview of Microplastic Removal From the Aquatic Environment}

\begin{abstract}
Plastic products are used by most societies worldwide and their production has increased dramatically since their initial commercial development. Particles smaller than $5 \mathrm{~mm}$ are defined as microplastic. Microplastics, which have become the most important pollutant in recent years, cause serious accumulation and danger in all compartments of the ecosystem. In this study, the results and comparisons of the studies on the structure of microplastics and their removal from the aquatic environment until today were made
\end{abstract}

Keywords: Microplastic Pollution, Removal Methods, Aquatic Environment.

\footnotetext{
* Sorumlu Yazar: olcayozer@mersin.edu.tr
} 


\section{Giriş}

Doğaya ulaşan plastiklerin parçalanması, bozunması ile olusan $5 \mathrm{~mm}$ boyutundaki plastikler mikroplastik olarak adlandırılmaktadır [1]. Bugüne kadar yapılan çalışmalarda mikroplastiklerin okyanus sedimentlerinde [2], yüzey sularında $[3,4]$ var olduğunu ortaya koymuştur. Tüm bunların yanında, mikroplastiklerin bulundukları su ortamlarında var olan canlılar tarafında kullanıldığı ve bünyelerinde biriktirildiği de tespit edilmiştir[5].

Mikroplastikler, ev ve kişisel bakım ürünlerinde kullanılan hammaddeler olan birincil mikroplastikler ve ham plastik parçacıkların çevrede fiziksel, kimyasal ve biyolojik işlemlerle bozunmasından kaynaklanan ikincil mikroplastikler olarak sinıflandirılmaktadır [6].

Mikroplastiklerin uzun süreli dayanıklılık, polimerik yapıları ve farklı habitatlar arasında kolay taşınması nedeniyle kontrol altına alınması gereken bir kirletici olduğunu ortaya koyar. Plastik, petrokimya sanayiinde, petrol esaslı ürün veya yan ürünler ile doğal gazı hammadde olarak kullanıp bunların kimyasal dönüşümleri ile elde edilen önemli madde gruplarından birisidir. Bu nedenle plastik sanayisini, petrokimya sanayisinin bir alt sektörü olarak görmek mümkündür. Kullanım kolaylığı, ucuzluk, dayanıklılık, kolay işlenebilirlik vb. özelliklerinden dolayı kağıt, karton, cam, demir: pamuk, keten vb. hammaddelerden üretilen ürünlerin yerini alan plastik ürünleri, diğer taraftan da enerji dağıtımı, sulama, kanalizasyon, ulaşım gibi projelerde önemli ölçüde kullanım alanı bulunmaktadır [7]. Başlica ham polimerler arasında polietilen tereftalat (PET), poliüretan (PU), polistiren (PS), polivinilklorür (PVC), polipropilen (PP), polyesterler, polietilen (PE) ve poliamid (PA, naylon) bulunur. [8].

$\mathrm{Bu}$ çalışmada mikroplastiklerin sucul ortamdan gideriminde bugüne kadar kullanılan yöntemlerin kısaca özetleri ve etkinliği ortaya konulmaya çalışılmıştır.

\section{Mikroplastik, Polimerler Ve Katkı Maddeleri, Kaynakları}

Mikroplastikler birinci ve ikincil olarak iki ana kaynağa ayrılırlar. Birincil mikroplastikler kozmetik ve temizlik ürünlerinden gelen polimerik partiküller, plastik ürünlerin üretiminde kullanılan hammaddeler ve hava püskürtme için kullanılan plastik topaklar veya tozlar [9]; atmosferik koşullar altında, örneğin mekanik bozunma ve UV 1şığına maruz kalma gibi, daha büyük plastik parçaların aşamalı olarak parçalanarak ikincil mikroplastikleri oluştururlar [10]. Mikroplastiklerin yüzey alanlarının geniş olmasından dolayı bulundukları ortamlarda birikme, yoğunluklarının düşük olmasından dolayı da rüzgârlar, akıntılar ile yüzerek taşınma eğilimindedirler [11].

Yapılan çalışmalar atık su arıtma tesislerinin de önemli bir mikroplastik kaynağı olduğuna dikkat çekmektedir $[12,13]$. Dünya genelinde çok sayıda arıtma tesisinin okyanus ve deniz suyu yakınında yer alması nedeniyle de, tesislerin önemli miktarlarda mikroplastik salım kaynağına neden olduğunu göstermektedir. Birçok araştırmacı su arıtma tesislerinde mikroplastiklerin akıbetini, oluşumunu, tespitini ve uzaklaştırılmasını araştırmaktadır [5,14,15].

Deniz ve okyanuslara ulaşan mikroplastiklerin ana kaynakları, tatlı sular ve karasal ortamlardır. Yapılan araştırmalar nehirler yoluyla okyanuslara ulaşan mikroplastik çöpün toprakta bulunan partiküller içerdiğini ortaya çıkarmıştır [16]. Bu sonuçlar bazı karasal ve tatlı su alanlarındaki yüksek mikroplastik konsantrasyonlarının kanıtladığı gibi, tatlı suların ve toprağın da mikroplastik biriktiren alanlar olduğunu göstermiştir [17].

Gübre olarak kanalizasyon çamurunun kullanıldığı tarım topraklarının derin katmanlarında $(\sim 25 \mathrm{~cm})$ bulunan mikroplastik liflere rastlanılmış olup [18], katı ortamda da dayanaklı liflerin derinlere taşınabileceğini göstermiştir [19]. Akış halinde olan nehir sistemlerine bakıldığında ise, akış ile taşınan mikroplastiklerin nehrin enerjisinin düştüğü yerlerde çökme eğilimi göstereceği öngörülmüştür [20].

Mikroplastiklerin farklı şekillerde, küçük boyutlu, hafif ve düşük yoğunlukta oluşu; kanalizasyon, rüzgar ve diğer doğal akımlar tarafindan karada ve su sistemleri içinde uzun mesafeler boyunca yaygın olarak taşınmasına ve kolay dağılmasına katkıda bulunmaktadir [21].

Ayrıca, tırtıklı geometriye ve keskin uçlara sahip düzensiz şekilli mikroplastikler, yüzeye geri dönmek yerine su altında daha fazla tutulurken, küresel parçacıklar yüzeyde kalma konusunda daha yüksek bir eğilim gösterir [22].

\section{Mikroplastiklerin Gideriminde Sorpsiyon Ve Filtrasyon Yöntemleri}

\subsection{Yeşil Algler ile Adsorpsiyon}

Mikroplastikleirn dayanaklılıklıkları ve düşük bozunabilirlik özelliklerinden dolayı, bulundukları ortamdan giderimi oldukça önemlidir. Mikroplastiklerin geniş yüzey alanı/hacim oranları, parçalanmaya/bozunmaya karşı olan dayanıklıkları bulundukları su ortamında var olan kirleticileri adsorbe etmeye ve taşımaya elverişli kılar [23]. Sundbaek ve arkadaşları [24], Fucus vesiculosus adlı deniz mikroalginin adsorban olarak kullanıldığ adsorpsiyon deneylerinde, mikroplastik parçacıklarınını davranışını incelemişlerdir. Sonuçlar, deniz yosununun kesilmiş yüzeylerinin yakınında yüksek bir mikroplastik sorpsiyonu ( \% 94.5) gerçekleştiğini ortaya koymuştur. $\mathrm{Bu}$ durum, kesilen bölgelerde hücre duvarlarından salınan jelatinimsi, anyonik polisakkarit bir madde olan aljinat bileşiklerinin özellikleri sebebi ile açıklanmıştır.

Mikroalglerin küçük plastik parçacıkları adsorplama kapasiteleri üzerine yapılan diğer araştırmalar, mikroplastiklerin yüzey yükünün ve mikroalglerin yüzey karakterlerinin adsoprisyon veriminde etkili rolün olduğunu vurgulamaktadır [25].

Nolte ve arkadaşları [25] 20-500 nm boyutunda polistiren partiküllerinin, tek hücreli yeşil algler üzerine adsorpsiyonunu araştırmışlardır. Pozitif yüklü polistiren mikroplastiklerin, alg 
yüzeyinde negatif yüklü olanlara göre daha verimli bir şekilde adsorbe edildiği sonucuna varmışlardır. Yapılan çalışmalar, mikroplastiklerin alg yüzeyine adsorpsiyonunun parçacıkların yüzey yüküne bağlı olduğu, pozitif yüklü mikroplastiklerin daha verimli bir şekilde adsoprlanma eğilimi gösterdiğini ortaya koymuştur.

\subsection{Membran Teknolojisini İle Giderim}

Li ve arkadaşları [26], mikroplastiklerin sentetik bir atık sudan verimli bir şekilde uzaklaştırılması için dinamik membranların kullandıkları bir çalışma gerçekleştirmişlerdir. Sentetik atık suyun filtrelenmesi sırasında $90 \mu \mathrm{m}$ destek ağlı bir diatomit platformunda oluşturulan dinamik membranların giderim verimliliğine giriş suyu ve partikül konsantrasyonunun etkisini araştırmışlardır. Giriş için 195 NTU olan bulanıklık değerinin, 20 dakikada çıkış suyunda için 1'in altına düşürülerek mükemmel bir mikroplastik filtrasyonu elde etmişlerdir [21].

Membran biyoreaktörleri, mikro boyutlu plastiklerin çıkarılması için basit dinamik membranlardan daha yüksek kapasite sergilerler [27,28].Çok çeşitli karmaşık endüstriyel atık suların membran biyoreaktörler tarafindan başarılı bir şekilde uzaklaştırılması, bu teknolojinin polimerik artıklar ve mikroplastikler gibi yüksek mukavemetli kirleticilerin arıtılması için de uygun olduğunu onaylamaktadır [29].

Talvit ve arkadaşları [28], membran biyoreaktör, disk filtre, hızlı kum süzme ve çözünmüş hava doldurma dahil olmak üzere gelişmiş son aşama arıtma teknolojilerini kullanarak atık su arıtma tesisi çıkış sularından çeşitli mikroplastik türlerinin giderimini araştırmışlardır. Membran biyoreaktörün, sudaki mikroplastiklerin \%99.9'unu şekillerinden bağımsız olarak, uzaklaştırdığını ortaya koymuştur.

Bugüne kadar yapılan çalışma sonuçları membran teknolojilerinin mikroplastikleri su ortamlarından uzaklaştırmak için başarıyla kullanılabileceğini göstermiştir. Gözenekli membranların biyolojik işlemlerle kombinasyonu, giderme verimini \%99,9'a kadar artırabileceği ortaya konulmuştur.

\subsection{Atıksu Arıtma Tesislerinde Gelişmiş Filtrasyon Teknolojileri Kullanılarak Giderim}

Lares ve arkadaşları [27], mikroplastiklerin uzaklaştırılması için pilot ölçekli, birleşik membran biyoreaktör-geleneksel aktif çamur metodolojisine dayalı olarak çalışan bir belediye atıksu arıtma tesisinin performansını incelemişlerdir. 3 ay süren çalışmalarında atık su örneklerini Finlandiya'nın Mikkeli şehir merkezinin yanında bulunan bir belediye su arıtma tesisinden temin etmişlerdir. Sonuçları, geleneksel aktif çamur arıtma sistemine (\%98.3) kıyasla bir membran biyoreaktör kullanılarak mikroplastiklerin (\%99.4) daha iyi uzaklaştırıldığını ortaya koymuştur.

Çin'in Changzhou kentindeki 11 atık su arıtma tesisi çıkış suyunda miktar, renk, şekil ve boyut parametrelinin arıtma tesisinin mikroplastikleri giderim verimlilikleri üzerindeki etkisini incelenmiştir [30]. Yüzdürme, çöktürme ve süzme işlemleri gibi çeşitli arıtma adımlarını kullanan tüm tesislerin mikroplastiklerin \%90'ından fazlasını sulardan arındırdığını ortaya koymuşlardır.
Giderim verimlerinde değişkenliğe neden olan en önemli nedenler günlük işlem hacmi, ham suyun karakteri ve arıtma proseslerinin türü olabilir. Genel olarak, sorpsiyon ve filtrasyon metodolojileri, mikroplastik içeren atık suların arıtılmasında, esas olarak biyolojik ve çökeltme prosesleri gibi diğer prosedürlerle birlikte iyi bir verimlilik göstermektedir. Daha yüksek giderim verimi elde etmek için, atık su arıtma tesisinde diğer gelişmiş fiziksel-kimyasal arıtmalarla eşzamanlı olarak membran biyoreaktörler kullanılmalıdır.

\subsection{Mikroplastik Gideriminde Kimyasal Yöntemler}

Dünya çapındaki birçok atık su arıtma tesisi, sudan ayrılması daha kolay olan büyük kirletici partikülleri oluşturmak için koagülasyon ve aglomerasyon proseslerini kullanır [31]. Bu prosesler, kompleksleşme mekanizmaları aracılığıyla küçük parçacıkları bağlamak ve böylece atık parçacıklar arasında güçlü bağlar oluşturmak için $\mathrm{Fe}$ ve $\mathrm{Al}$ bazlı tuzları ve koagülant kullanımını içerir [32].

Ariza-Tarazona ve arkadaşları [33] demir, alüminyum tuzu ve ultrafiltrasyon kullanarak polietilen mikroplastiklerin sudan giderimini araştırmışlardır. Deneyler $\mathrm{Al}^{3+}$ ve $\mathrm{Fe}^{3+}$ iyonlarının farklı konsantrasyonları altında gerçekleştirildi ve sonuçlar $\mathrm{Al}^{3+1}$ nın $\mathrm{Fe}^{3+1}$ dan daha iyi performansa sahip olduğunu göstermiştir.

$\mathrm{Bu}$ alanda araştırmacılar ayrıca, karıştırmalı, kesikli reaktörde polietilen mikroplastiklerinin giderimi için çamur minimizasyonu, enerji verimliliği, maliyet etkinliği ve otomasyonda esneklik sağlayan sağlam ve çevreyle uyumlu elektrokoagülasyon tekniğini kullanmışlardır [34].

Metal hidroksit koagülantinın yerinde oluşumu, suda elektrotlardan salınan $\mathrm{Fe}^{2+}$ ve $\mathrm{Al}^{3+}$ gibi metal iyonlarının ortamın hidroksil anyonları ile reaksiyonu ile başlatılır. Üretilen koagülantlar kolloidleri parçalar ve asılı mikropartiküllerin yüzey yüklerini stabilize eder, bu da partiküllerin van der Waals kuvvetleri aracılığıyla etkileşimler yapmak için yeterince birbirine yaklaşmasını sağlar [35].Koagülantlar, atık suda asılı kalan mikroplastikleri yakalamak için aynı anda bir kapan oluşturur. Yapılan çalışmanın sonucunda $\% 90$ verim elde edildiği rapor edilmiştir.

Mikroplastiklerin bozunma mekanizmaları tam olarak bilinmemektedir. Brandon ve arkadaşları [36], simüle edilmiş gerçekçi hava koşulları altında 3 yıl boyunca polipropilen ve polietilen dahil olmak üzere iki tür mikro plastiğin kimyasal yapısındaki değişiklikleri incelemişlerdir. Yapılan FTIR analizlerine göre, karbonil, hidroksil ve karbon-oksijen bağlarında zamanla doğrusal olmayan değişiklikler buldular, bununda mikroplastiklerin yavaş bozunmasına işaret ettiğini rapor etmişlerdir.

\section{Biyolojik Giderim}

\subsection{Deniz Organizmaları Tarafindan Mikroplastiklerin Giderimi}

Bugüne kadar yayınlanan çalışma sonuçlarına göre, doğal ve sentetik makroplastiklerin biyolojik bozunmasının mümkün olduğu yönündedir [37]. Kabuklu planktonik olan Antarctic Krill tarafindan yutulan polietilen mikroplastiklerin parçalanması ve 
boyut değişimi, Avustralya'da bir grup araştırmacı tarafından incelenmiştir [38]. Mikroplastikler ile zooplankton arasındaki parçalanma mekanizma türü hala belirsizliğini koruyor olmasına karşın, daha küçük mikroplastiklerin çevresel koşullar altında çok kolay parçalanabileceğini doğrulamıştır [39].

Cocca ve arkadaşları [40] tarafından yapılan çalışmada, iki tür deniz topluluğu kullanılarak (Agios ve Souda konsorsiyumu) deniz suyundan, yüksek yoğunluklu polietilen ikincil mikroplastiklerin giderimi araştırılmıştır. Sonuçlarına göre, Souda konsorsiyumunun daha yüksek mikroplastik giderimi sağladığı ve hücre içeriğinin ve popülasyonların izlenmesine ait sonuçlarda ise, mikroplastiklerin organizmaları beslemek için zengin bir karbon kaynağı olarak işlev gördüğünü ortaya koymuştur. Deneyler sırasında her iki topluluğunda protein içeriğinin azalırken, hücre karbonhidrat içeriğindeki artışı, mikrobiyal polimer bozulmasının ilk adımı olan mikroplastik yüzeylere yapışma eğilimi artışından kaynaklanmaktadır.

Paço ve arkadaşları [41], deniz ekosistemlerinde doğal olarak oluşan bir mantar olan Zalerion maritimum mantarının, kesikli reaktörde mikroplastiklerin kütle ve boyut varyasyonlarına dayalı polietilen mikroplastiklerin biyolojik bozunması için kullanımını araştırmalardır. Maruz kalma süresiyle birlikte protein miktarının azalması ve karbonhidrat artışı gibi biyolojik içerik ölçümlerinden elde edilen sonuçlar, Z. maritimum topluluğunun mikroplastikleri muhtemelen bir besin kaynağı olarak kullandığını ifade etmiştir.

\subsection{Bakteriler İle Mikroplastik Giderimi}

Auta ve arkadaşları [42], polietilen, polistiren, polietilen tereftalat ve polipropilenden oluşan farklı yapıda mikroplastiklerin, Bacillus cereus ve Bacillus gottheilii tarafından giderimini araştırmışlardır. Elektron mikroskobu ve FTIR analizleri kullanılarak morfolojik ve yapısal değişikliklerin araştırılmış, mikroplastik ağırlık kaybı ölçülerek biyolojik bozunma hızı değerlendirilmiştir. En hızlı kütle azalması ve en kısa bozunma yarı ömrü polistiren mikroplastikler için B. cereus izolatı kullanılarak bulunmuştur. FTIR analiziyle taranan bozunma sonuçlarına göre, bağ ayrılmaları ve kimyasal değişiklikleri karşılaştırarak, B. Gottheilii türünün mikroplastik parçalamada en iyi olduğunu ortaya çıkarmıştır.

\section{Sonuçlar}

$\mathrm{Bu}$ çalışma günümüz dünyasının en güncel kirlilik sorunlarının başında gelen, davranışı, kaynağı, giderimi konularında son 5 yılda yapılan çalışmalar ile aydınlatılmaya çalışılan mikroplastik kirliliğinin giderim yöntemleri hakkında derleme çalışmasıdır.

Mikroplastik gideriminde kullanılan;

- Yeşil mikroalglerin kesilen yüzeylerinin mikroplastik parçacıkları adsorplamaya karşı yüksek afinitesi olduğunu ve verimin mikroplastik yüzey yüküne dayalı olduğunu,

- Dinamik membranların düşük filtrasyon direnci, düşük trans membran basıncı, kolay kullanımı, ve kimyasal kullanılmadan aritılması,

- Membran biyoreaktörlerinin gözenekli membranlarla ileri arıtma yöntemlerinin kombine kullanılması
- Atıksu aritma tesislerinin sorpsiyon-biyolojik proseslerince kombine arıtımı, düşük bakım maliyetleri, basit kullanımı,

- Klasik koagülasyon ve çöktürme metotlarının, mikropartiküllerin gideriminde basit birmekanizma ile gideriminin sağlaması ve çalışma şartlarının kontrol edilebilmesi,

- Elektrokoagülasyon metodunun en küçük parçacıkların giderilmesi, minimum çamur üretimi, enerji verimliliği, maliyet etkinliği ve otomasyonda ki esnekliği,

- Biyolojik parçalanma ile büyük ölçekli kullanımda basitlik ve güvenlik, düşük işletme maliyetleri, farklı ortamlarda pratik uygulanabilirliği, çok çeşitli atık su özelliklerini ve akışlarını idare etme esnekliği gibi avantajları vardır.

Yapılan bu derleme ile sulardan mikroplastik giderim verimi sonuçları sırasıyla, \% 99 ile membran reaktör sistemlerinden, $\% 95$ ile klasik atık su arıtma tesislerinden, \%94 ile yeşil alg adsorpsiyonu , \%90 ile elektrokoagülasyon ve \%61 lik verim ile de klasik koagülasyon metotlarından elde edildiği görülmüştür.

Membran biyoreaktörlerle birleştirilmiş adsorpsiyon /filtrasyon prosesleri, atıksu arıtma tesislerine giren giriş suyunda yüksek oranda mikroplastiklerin giderilmesine imkan sağladığı, ancak atık suların doğrudan sucul ortamlara deşarjı ile de mikroplastik kaynakları olarak ana kaynak oluşturduğu ortaya konulmuştur.

Elektrokoagülasyon ve koagülasyon proseslerinin, mikroplastiklerin gideriminde güvenilir teknikler olduğu, ancak yüksek verim elde etmek için ekstra filtrasyon aşamalarıyla birleştirilmesi gerektiği yapılan çalışmaların sonuçları ile ortaya çıkmıştır.

FTIR ve elektron mikroskobu analizleri, bozunma işlemi sırasında herhangi bir yapısal değişikliği aydınlatmak için yaygın olarak kullanılır. Bakteri suşları ve deniz organizmaları üzerinde biyolojik parçalanmanın araştırma sonuçları biyolojik giderim için oksidatif mekanizmayı öne çıkarmıştır.

Doğada meydana gelen kirliliği önlemede, kaynakların azaltılması önemli iken kirliliğin giderimi de doğal ekosistemlerin dengesi için önemlidir. Dünya genelinde mikroplastik kaynaklarının azaltılması için birçok çalışma başlatılmış fakat henüz var olan kirliliğin büyüklüğü tam olarak tespit edilememiştir. $\mathrm{Bu}$ kirleticilerin yapılarından kaynaklı dayanıklılıkları ise, giderim yöntemlerinin kirliliği kontrol altına alınmasında önemli bir rol üstlenmektedir.

\section{Kaynaklar}

[1] Zhang K, Shi H, Peng J, Wang Y, Xiong X, Wu C, Lam PK (2018) Microplastic pollution in China's inland water systems: a review of findings, methods, characteristics, effects, and management. Sci Total Environ 630:1641-1653.

[2] Van Cauwenberghe L, Vanreusel A, Mees J, Janssen CR (2013) Micro- plastic pollution in deep-sea sediments. Environ Pollut 182:495-499.

[3] Faure F, Demars C, Wieser O, Kunz M, De Alencastro LF (2015) Plastic pollution in Swiss surface waters: nature and concentrations,interaction with pollutants. Environ Chem 12(5):582-591 
[4] Law KL, Morét-Ferguson SE, Goodwin DS, Zettler ER, DeForce E, Kukulka T, Proskurowski G (2014) Distribution of surface plastic debris in the eastern Pacific Ocean from an 11-year data set Environ Sci Technol 48(9):4732-4738.

[5] Sun J, Dai X, Wang Q, van Loosdrecht MC, Ni B-J (2019) Microplastics in wastewater treatment plants: detection, occurrence and removal. Water Res 152:21-37

[6] Galgani F, Hanke G, Werner S, De Vrees L (2013) Marine litter within the European marine strategy framework directive. ICES J Mar Sci 70(6):1055-1064.

[7] Güler Ç., Çobanoglu Z. PLASTIKLER. TC.Să̆glık Bakanlı̆̆l, Ankara 1997

[8] Liu P, Qian L, Wang H, Zhan X, Lu K, Gu C, Gao S (2019) New insights into the aging behavior of microplastics accelerated by advanced oxidation processes. Environ Sci Technol 53:3579-3588.

[9] Jiang J-Q (2018) Occurrence of microplastics and its pollution in the environment: a review. Sustain Prod Consum 13:1623.

[10] Thompson RC, Olsen Y, Mitchell RP, Davis A, Rowland SJ, John AW, McGonigle D, Russell AE (2004) Lost at sea: where is all the plastic Science 304(5672):838

[11] Anbumani, S.ve Kakkar, P. (2018). Ecotoxicological effects of microplastics on biota: a review, Environmental Science and Pollutution Research, 25(15), 14373-14396.

[12] Browne MA, Crump P, Niven SJ, Teuten E, Tonkin A, Galloway T, Thompson R (2011) Accumulation of microplastic on shorelines worldwide: sources and sinks. Environ Sci Technol 45(21):9175-9179.

[13] Long Z, Pan Z, Wang W, Ren J, Yu X, Lin L, Lin H, Chen H, Jin X (2019) Microplastic abundance, characteristics, and removal in wastewater treatment plants in a coastal city of China. Water Res 155:255-265.

[14] Beljanski A (2016) Efficiency and effectiveness of a lowcost, self- cleaning microplastic filtering system for wastewater treatment plants. 2016 NCUR

[15] Carr SA, Liu J, Tesoro AG (2016) Transport and fate of microplastic particles in wastewater treatment plants. Water Res 91:174-182.

[16] Horton AA, Svendsen C, Williams RJ, Spurgeon DJ, Lahive E (2017) Large microplastic particles in sediments of tributaries of the River Thames, UK-Abundance, sources and methods for effective quantification. Mar Pollut Bull 114(1):218-226.

[17] Nizzetto L, Futter M, Langaas S (2016) Are agricultural soils dumps for microplastics of urban origin. Environ Sci Technol 50(20):10777-10779

[18] Zubris KAV, Richards BK (2005) Synthetic fibers as an indicator of land application of sludge. Environ Pollut 138(2):201-211.

[19] Lwanga EH, Gertsen H, Gooren H, Peters P, Salánki T, van der Ploeg M, Besseling E, Koelmans AA, Geissen V (2017) Incorporation of microplastics from litter into burrows of Lumbricus terrestris. Environ Pollut 220:523-531

[20] Corcoran PL, Norris T, Ceccanese T, Walzak MJ, Helm PA, Marvin CH (2015) Hidden plastics of Lake Ontario, Canada and their potential preservation in the sediment record. Environ Pollut 204:17-25.

[21] Horton AA, Dixon SJ (2018) Microplastics: an introduction to environmental transport processes. Wiley Interdiscip Rev Water 5(2):1268-1283.

[22] Lagarde F, Olivier O, Zanella M, Daniel P, Hiard S, Caruso A (2016) Microplastic interactions with freshwater microalgae: hetero aggregation and changes in plastic density appear strongly dependent on polymer type. Environ Pollut 215:331-339.

[23] Rios LM, Moore C, Jones PR (2007) Persistent organic pollutants carried by synthetic polymers in the ocean environment. Mar Pollut Bull 54(8):1230-1237.

[24] Sundbæk KB, Koch IDW, Villaro CG, Rasmussen NS, Holdt SL, Hartmann NB (2018) Sorption of fluorescent polystyrene microplastic particles to edible seaweed Fucus vesiculosus. J Appl Phycol 30(5):2923-2927

[25] Nolte TM, Hartmann NB, Kleijn JM, Garnæs J, van de Meent D, Hendriks AJ, Baun A (2017) The toxicity of plastic nanopar- ticles to green algae as influenced by surface modification, medium hardness and cellular adsorption. Aquat Toxicol 183:11-20.

[26] Li L, Xu G, Yu H, Xing J (2018b) Dynamic membrane for microparticle removal in wastewater treatment: performance and influencing factors. Sci Total Environ 627:332-340.

[27] Lares M, Ncibi MC, Sillanpää M, Sillanpää M (2018) Occurrence, identification and removal of microplastic particles and fibers in conventional activated sludge process and advanced MBR technology. Water Res 133:236-246.

[28] Talvitie J, Mikola A, Koistinen A, Setälä O (2017a) Solutions to microplastic pollution removal of microplastics from wastewater effluent with advanced wastewater treatment technologies. Water Res 123:401-407

[29] Gurung K, Ncibi MC, Fontmorin J-M, Särkkä H, Sillanpää $M$ (2016) Incorporating submerged MBR in conventional activated sludgeprocess for municipal wastewater treatment: a fea

[30] Ma B, Xue W, Ding Y, Hu C, Liu H, Qu J (2019) Removal characteristics of microplastics by Fe-based coagulants during drinking water treatment. J Environ Sci 78:267-275.

[31] Shirasaki N, Matsushita T, Matsui Y, Marubayashi T (2016) Effect of aluminum hydrolyte species on human enterovirus removal from water during the coagulation process. Chem Eng J 284:786-793

[32] Chorghe D, Sari MA, Chellam S (2017) Boron removal from hydraulic fracturing wastewater by aluminum and iron coagulation: mechanisms and limitations. Water Res 126:481-487.

[33] Ariza-Tarazona MC, Villarreal-Chiu JF, Barbieri V, Siligardi C, Cedillo-González EI (2019) New strategy for microplastic degradation: green photocatalysis using a protein-based porous N-TiO 2 semiconductor. Ceram Int 45(7):9618-9624.

[34] Perren W, Wojtasik A, Cai Q (2018) Removal of microbeads from wastewater using electrocoagulation. ACS Omega 3(3):3357-3364.

[35] Akbal F, Camc1 S (2011) Copper, chromium and nickel removal from metal plating wastewater by electrocoagulation. Desalination 269(1-3):214-222

[36] Brandon J, Goldstein M, Ohman MD (2016) Long-term aging and degradation of microplastic particles: comparing in situ oceanic and experimental weathering patterns. Mar Pollut Bull 110(1):299-308.

[37] Ahmed T, Shahid M, Azeem F, Rasul I, Shah AA, Noman M, Hameed A, Manzoor N, Manzoor I, Muhammad S (2018) Biodegradation of plastics: current scenario and future prospects for environmental safety. Environ Sci Pollut Res 25(8):7287-7298.

[38] Dawson AL, Kawaguchi S, King CK, Townsend KA, King R, Huston WM, Nash SMB (2018) Turning microplastics into 
nanoplastics through digestive fragmentation by Antarctic krill. Nat Commun 9(1):1001.

[39] Ter Halle A, Ladirat L, Gendre X, Goudounèche D, Pusineri C, Routaboul C, Tenailleau C, Duployer B, Perez E (2016) Understanding the fragmentation pattern of marine plastic debris. EnvironSci Technol 50(11):5668-5675.

[40] Cocca M, Di Pace E, Errico ME, Gentile G, Montarsolo A, Mossotti R (2017) Proceedings of the international conference on microplastic pollution in the mediterranean sea. Springer, Berlin

[41] Paço A, Duarte K, da Costa JP, Santos PS, Pereira R, Pereira M,Freitas AC, Duarte AC, Rocha-Santos TA (2017) Biodegradation of polyethylene microplastics by the marine fungus Zalerion maritimum. Sci Total Environ 586:10-15.

[42] Auta H, Emenike C, Fauziah S (2017) Screening of Bacillus strains isolated from mangrove ecosystems in Peninsular Malaysia for microplastic degradation. Environ Pollut 231:1552-1559. 